\title{
Internal cardioversion of persistent atrial fibrillation in implantable cardioverter defibrillator patients: the juice is not worth the squeeze
}

\author{
W. R. Berger • R. E. Knops • J. R. de Groot
}

Published online: 24 October 2013

(C) The Author(s) 2013. This article is published with open access at Springerlink.com

Atrial fibrillation (AF) is the most common arrhythmia and its prevalence and incidence increase with age, but also with cardiovascular morbidity, such as hypertension, diabetes, vascular and valvular disease and heart failure. Indeed, in patients with implantable cardioverter defibrillators (ICD), who usually have one or more of these predisposing factors, a history of AF was present in $33 \%$ [1]. In this patient group AF can be symptomatic for example by causing palpitations, dyspnoea and fatigue, but can also worsen heart failure and lead to inappropriate ICD discharges.

The electrophysiological substrate of persistent AF is heterogeneous, but the fact that the arrhythmia does not terminate spontaneously, as paroxysmal AF does, and may require cardioversion, triggers the impression that the substrate is more advanced in this type of AF. This is evidenced by more left atrial fibrosis, dilated atria and lower intracardial electrogram amplitudes in persistent versus paroxysmal $\mathrm{AF}[2,3]$.

Despite the fact that pharmacological cardioversion is recommended as the first-line treatment option in patients with recent-onset $\mathrm{AF}$ [4], electrical cardioversion (ECV) is highly efficacious in restoring sinus rhythm in patients with $\mathrm{AF}$, and performed on a daily basis in most hospitals.

Editorial comment to: Limantoro et al. 'Low efficacy of cardioversion of persistent atrial fibrillation with the implantable cardioverter defibrillator' doi:10.1007/s12471-013-0474-Z

W. R. Berger · R. E. Knops · J. R. de Groot

Heart Center, Department of Cardiology, Academic Medical Center,

Amsterdam, the Netherlands

J. R. de Groot $(\bowtie)$

Heart Center, Department of Cardiology, Academisch Medisch Centrum, Meibergdreef 9, 1100 DD Amsterdam, the Netherlands

e-mail: j.r.degroot@amc.uva.nl
Patients with ICDs in this respect form an interesting subgroup, while they carry their cardioverter subcutaneously or under the pectoral muscle. Indeed, it was shown in a population of patients with cardiac resynchronisation therapy that internal cardioversion was associated with $82 \%$ of restoration of sinus rhythm [5]. Aside from the demonstration of feasibility, the efficacy seems somewhat lower than conventional, external ECV and the question arises whether internal defibrillation should be implemented into clinical practice.

In this issue of the Netherlands Heart Journal Limantoro et al. describe the efficacy of internal cardioversion using the ICD in all-comers with persistent AF [6]. They show a disappointingly low cardioversion rate of $33 \%$ among the 27 patients with persistent $\mathrm{AF}$ in whom internal cardioversion was attempted. Patients with failed internal cardioversion subsequently underwent external electrical cardioversion, which was effective in all of the patients.

Interestingly, looking further into the characteristics of the patients who failed internal cardioversion, Limantoro et al. report that those patients had significantly larger left atrial volumes (146 $\pm 44 \mathrm{ml}$ vs. $99 \pm 36 \mathrm{ml})$, a longer total AF history (40 (5-75) vs. $2(0-17)$ months) and shorter right atrial cycle length (169 (152-183) ms vs. 227 (186-255) ms), as recorded from the atrial lead of the ICD. The investigators suggest that the atrial substrate, as clinically assessed with these parameters, negatively affects the atrial defibrillation threshold for internal cardioversion of AF, which is supported by the even lower efficacy of $10 \%$ of subsequent internally delivered shocks. Furthermore, they describe that three out of four (75\%) patients with a dual-coil ICD had successful internal cardioversion. On the other hand, only $28 \%$ of 23 patients with a single-coil ICD were cardioverted internally, demonstrating that internal cardioversion was particularly ineffective in this group. Therefore, they emphasise the importance of patient selection: Patients with a short history of AF and small atria may be suitable for internal cardioversion, but patients 
with more structurally remodelled atria should rather directly undergo external cardioversion to achieve sinus rhythm. As of today, we do not know whether the three parameters mentioned above are sufficient to determine the extent of atrial substrate remodelling in these patients. It can be hypothesised that the amount of fibrosis, which is very hard to determine echocardiographically (although atrial fibrosis is associated with left atrial size), may have an important contribution to the atrial defibrillation threshold. Potentially, there is an unrecognised group of patients with remodelled atria who are not detected with these three parameters and in whom internal cardioversion may be evenly unsuccessful.

It is tempting to seek the characteristics of the atrial substrate as a determinant of internal cardioversion success, but against the background of the data that Limantaro et al. describe, the most important question is why internal cardioversion should be considered in ICD patients at all.

One reason could be that external cardioversion could damage the device. There are indeed older case reports on broken implanted rhythm devices after direct current shocks requiring replacement of the device [7]. Generally, it is advised to place the paddles of the external defibrillator in an anteroposterior manner to avoid current flow through the device causing device and/or electrode dysfunction. With external cardioversion being performed almost daily in most cardiac care units, shock paddles could theoretically be misplaced and cause damage to the ICD. However, Manegold et al. [8] showed that using the appropriate (antero-posterior) paddle position, external cardioversion for $\mathrm{AF}$ is safe and effective in patients with implanted rhythm devices and no device or lead dysfunction was reported in any of their patients.

Another advantage could be that less shock energy is required with internal cardioversion as compared with $\mathrm{ECV}$, but the clinical interpretation thereof is unclear. It seems simple logic that more shocks are worse than fewer, and that the first shock should be aimed at restoring sinus rhythm in as many patients as possible.

Other sources of potential adverse effects associated with cardioversion include the risk of thromboembolic complications, for which the use of anticoagulants is clearly defined in the guidelines [4] and complications associated with the use of general anaesthesia. These factors, however, are present to the same extent in patients being cardioverted internally as externally. The use of general anaesthesia, and therefore the presence of an anaesthesiologist at the site, as described by Limantaro et al., and conform the current clinical practice in most centres, importantly limits the potential benefits of internal cardioversion. Additionally, for internal cardioversion an ICD technician is needed to program the ICD and apply the internal shock. The requirement of the presence of several professionals in performing the procedure can be a logistic disadvantage of internal cardioversion and result in significantly higher costs.
Finally, as Limantoro et al. discuss, extra shocks performed with an implantable cardioverter defibrillator may have a negative impact on battery lifetime. Battery depletion is the major cause of ICD replacement, which is associated with higher risks for the patient [9]. Moreover, saving battery lifetime will reduce the number of ICD generator changes, maybe not on the level of the individual patient, but certainly on a population level. Consequently, saving battery lifetime is expected to reduce complications and costs. This is especially true in patients with frequent recurrences of $\mathrm{AF}$, something that is not uncommon in persistent AF. Hence, battery depletion has to be taken into account when considering internal cardioversion.

Taking the above argumentation into account Limantoro et al. raise the justified question if internal cardioversion should be the preferred treatment of choice in patients with an ICD. As a conclusion from the disappointingly low efficacy rate for internal cardioversion, they answer that question with 'no' and they have indeed discontinued this practice in their own hospital. Internal cardioversion seems to have no significant advantages over external cardioversion. Determining the atrial substrate of AF, although scientifically very interesting for a better understanding the disease, may therefore be futile when choosing the cardioversion strategy in patients with an ICD and persistent AF. It may be, however, of importance to find parameters that can determine patients in whom atrial remodelling is advanced and who will experience frequent recurrences, despite cardioversion. Since ECV was eventually successful in all the patients in the study by Limantoro et al., this determination may be relevant for patient prognosis, but not for cardioversion success.

The goal of cardioversion in patients with $\mathrm{AF}$ is restoration of sinus rhythm, while applying the least number of shocks. Apart from the patients with recent-onset AF, in whom pharmacological cardioversion is applied, the results of the study by Limantoro et al. point us in the direction of applying external cardioversion as treatment of choice for persistent $\mathrm{AF}$, whether the patient carries an ICD or not.

Funding None

Conflicts of interest None declared.

Open Access This article is distributed under the terms of the Creative Commons Attribution License which permits any use, distribution, and reproduction in any medium, provided the original author(s) and the source are credited.

\section{References}

1. Haines DE, Wang Y, Curtis J. Implantable cardioverter-defibrillator registry risk score models for acute procedural complications or death after implantable cardioverter-defibrillator implantation. Circulation. 2011;123(19):2069-76. 
2. Burstein B, Nattel S. Atrial fibrosis: mechanisms and clinical relevance in atrial fibrillation. J Am Coll Cardiol. 2008;51(8):802-9.

3. Morillo CA, Klein GJ, Jones DL, et al. Chronic rapid atrial pacing. Structural, functional, and electrophysiological characteristics of a new model of sustained atrial fibrillation. Circulation. 1995;91(5):1588-95.

4. Camm AJ, Kirchhof P, Lip GY, et al. Guidelines for the management of atrial fibrillation: the Task Force for the Management of Atrial Fibrillation of the European Society of Cardiology (ESC). Europace. 2010;12(10):1360-420.

5. Turco P, D'Onofrio A, Stabile G, et al. Feasibility and efficacy of electrical cardioversion after cardiac resynchronization implantation in patients with permanent atrial fibrillation. J Interv Card Electrophysiol. 2012;35(3):331-6.

6. Limantoro I, Vernooy K, Weijs B, Pisters R, Debie L, Crijns HJ, Blaauw Y. Low efficacy of cardioversion of persistent atrial fibrillation with the implantable cardioverter-defibrillator. Neth Heart J 2013. doi: 10.1007/s12471-013-0474-z.

7. Waller C, Callies F, Langenfeld H. Adverse effects of direct current cardioversion on cardiac pacemakers and electrodes Is external cardioversion contraindicated in patients with permanent pacing systems? Europace. 2004;6(2):165-8.

8. Manegold JC, Israel CW, Ehrlich JR, et al. External cardioversion of atrial fibrillation in patients with implanted pacemaker or cardioverter-defibrillator systems: a randomized comparison of monophasic and biphasic shock energy application. Eur Heart J. 2007;28(14):1731-8.

9. Thijssen J, Borleffs CJ, van Rees JB, et al. Implantable cardioverterdefibrillator longevity under clinical circumstances: an analysis according to device type, generation, and manufacturer. Heart Rhythm. 2012;9(4):513-9. 